\title{
"Jihad against Palestinians? \\ The Herostratos syndrome and the paradox of targeting European Jews"
}

Jean-Paul Azam and Mario Ferrero 
December 15, 2017

\title{
Jihad against Palestinians?
}

\section{The Herostratos syndrome and the paradox of targeting European Jews}

\author{
Jean-Paul Azam, Toulouse School of Economics, e-mail jean-paul.azam@ut-capitole.fr \\ Mario Ferrero ${ }^{*}$, University of Eastern Piedmont, e-mail mario.ferrero@uniupo.it
}

\begin{abstract}
This paper addresses the waves of mass killings recently perpetrated by individuals with a weak or nonexistent ideological motivation, whose acts either appear to contradict their purported political cause or are admittedly driven by a quest for notoriety. Examples range from killers who have been waging jihad against European Jews to unattached mass killers such as the Germanwings pilot to the perpetrators of mass school shootings in America and worldwide. We argue that these phenomena can be understood as instances of the Herostratos syndrome, which has been known for thousands of years as characterizing the behavior of people who seek to survive in the collective memory by excelling in their infamous acts. We provide a model of hybrid killers which accommodates the Herostratic motive alongside a political motive and characterize a well-behaved Nash equilibrium where Herostratic killers are competing with one another with a view to make a name for themselves in infamy. The policy implications point toward reducing the publicity the killers enjoy, thus frustrating their quest for notoriety.
\end{abstract}

Keywords: terrorism; Herostratos; cult; competition for infamy; jihad; school shootings JEL codes: C72; D74

\footnotetext{
* Corresponding author
} 


\section{Introduction}

Although Mohamed Merah, Mehdi Nemmouche and Amedy Coulibali have claimed to kill in the name of Global Jihad, they have indulged in the deliberate killing of Jews in Toulouse, Brussels and Paris respectively. The main impact of such killing of Jewish civilians in Western Europe is to provide many others with an incentive to perform their Alya, i.e. to migrate to Israel. According to some estimates by Jewish organizations close to the Israeli Embassy in Paris, several hundred French families have thus migrated to Israel in the wake of these killings of Jews in France and Belgium above the normal trend after Merah's 2012 attack at the Ozar Hatorah school in Toulouse. In 2015 alone, 7,900 French Jews have thus migrated to Israel. This is precisely the opposite effect to what Hamas and Hezbollah are trying to achieve by running their very costly campaigns of mortar shelling inside Israel or of suicide attacks against Israelis. Their aim is to maintain in Israel a sustained level of insecurity high enough to either discourage Jewish immigration there or even to convince some Israeli citizens to migrate abroad, to Europe or the US, in order to escape from that insecurity. Even the most devoted Zionists cannot hope to trigger so many Alyas even by investing large sums of money for helping migrants as the three French Muslim killers have done. Although it is too early to provide any estimate at the time of writing, it is likely that the November 2015 lethal attacks in Paris will have a similar impact, although they did not target Jews specifically. Still, the Bataclan theater, where more than 100 people were gunned down, is located quite close to an area where many Jews are known to live and to run a lot of fashionable shops. Hezbollah's leader Hasan Nasrallah has even formally condemned some of the recent terrorist attacks in France, saying on January 9, 2015, that "extremists have done more harm to Islam than cartoons", as well as other attacks outside the Middle East on other occasions ever since $9 / 11$. 
This seeming strategic inconsistency puts out a challenge to the rational-choice theorist, echoed in the media using expressions like "brainwashing", "radicalization", etc. to "explain" this seemingly irrational behavior. Rational-choice theory would instead take rationality of the actors as an untestable postulate and would use revealed preference theory to try and decipher the agenda hidden behind the apparent contradictions between the political claims voiced by these killers or their entourage and the predictable outcomes of their acts.

The present paper - a substantial extension of a previous note ${ }^{1}$ - explores how the socalled "Herostratos Syndrome" (Borowitz, 2005) can actually help us to answer the question of what these killers really sought to maximize when they launched their attacks against European Jews despite their highly predictable negative consequences for the Palestinian cause. This syndrome has been known for more than two millennia and refers to killers and arsonists who perpetrate odious attacks for the sake of self-glorification. We argue that this type of motivation has a much broader domain of application than just Global Jihad, as Western countries have witnessed recently many other violent and spectacular attacks that seem to aim just at making a name for the killers. There is a wide diversity of killers, whose self-proclaimed objectives blend in different proportions some claims to fight for major ideological causes, ranging from Global Jihad to White Supremacy (like Anders Breivik who in July 2011 massacred 77 people in Norway, most of whom, paradoxically, were white kids) to Marxism-Leninism (like the notorious Carlos the Jackal in the $20^{\text {th }}$ century, who turned coat many times), with an obvious quest for celebrity. Hence, there might be another driver behind these terrorist attacks than just political causes. This diversity is accommodated in the model below by assuming hybrid motivations for the potential terrorists, where the Herostratos syndrome and the devotion to some cause may come in various proportions. The

\footnotetext{
${ }^{1}$ A very short presentation of our approach, including a brief description of the model and its policy implications, was published in the proceedings of the $16^{\text {th }} \mathrm{Jan}$ Tinbergen European Peace Science Conference (Azam and Ferrero, 2016). The present paper analyzes the full model with all the different cases (including the possibility of multiple equilibria), elaborates on its policy implications in detail, and addresses a broad variety of historical and current applications as a testing ground.
} 
benefit of embedding this hypothesis within such a model of hybrid killers is that many other potential applications come to mind to explain many other kinds of lethal attacks that are routinely observed all around the planet, be they self-proclaimed terrorist or otherwise. For example, many insurgencies invest in bombing pipelines, which often entails massive irreversible environmental damage, something that seems to contradict their claim to be working to enhance the welfare of their folks and their descendants. Similarly the massacre of more than a thousand Muslims in the Indian state of Gujarat in 2002 was perpetrated under the aegis of the Hindu right (Nussbaum, 2007) although it was bound to trigger an increased support among Indian Muslims for the Global Jihad movement harbored by neighboring and rival Pakistan. The subsequent Mumbai killings then came as a deadly echo in 2008.

An additional layer of strategic inconsistency seems to challenge the rational choice theorist because some Islamist organizations seem to support this type of attacks within a Global Jihad framework. This is the case of the Islamic State in Iraq and al-Sham (ISIS), whose leader Abu Bakr al-Baghdadi has made violent declarations justifying the killing of Jews wherever they are. This indiscriminate anti-Semitic view finds also some support in the popular apocalyptic literature that flourished in Egypt and some other Middle Eastern countries (Filiu, 2011). In a typical apocalyptic fashion, some authors argue that strengthening the state of Israel would hasten the day of the final battle where Islam will crush the Byzantine army, i.e., the Christian Zionist powers. After thoroughly reviewing this literature, Filiu concludes (tongue in cheek): "Generally speaking, inhabitants of the West Bank and Gaza seemed less fond of apocalyptic imaginings than people in neighboring countries" (Filiu, 2011, p.135). We argue instead that this position is part of a rational strategy aimed at leveraging the Herostratos syndrome to recruit more Jihadists by offering an alternative, media-intensive communication network. In such a network, the new recruits are bound to reach instant infamous stardom for their participation in gory videos, where beheadings and 
other blood shedding acts are broadcasted online world-wide (Kepel, 2015, Nesser, 2015, Stern and Berger, 2015). Hence, behind the cover of a grand plan for apocalyptic Jihad, ISIS leadership is probably also advocating indiscriminate Jews killing as an additional incentive for individual European killers to join their cause as a shortcut to celebrity.

The remainder of this paper is organized as follows. The next section looks at some related literature, while section 3 reviews some empirical material, both historical and contemporary, that substantiates the Herostratos syndrome. Section 4 presents the model and section 5 works out its comparative statics to draw policy implications. The last section concludes.

\section{Literature}

The problem addressed in this paper - competition for infamy - seems to be unexplored in the economics and rational-choice literature. There are, however, two fields of research that are germane to it, though at some remove. One is the study of the supply side of suicide terrorism: the motivation of individuals willing to sacrifice their lives and their decision-making calculus. These individuals, however, are generally motivated by an ideology or inspired by a cause and act under the direction of, or with reference to, some political, religious, or military organization; by contrast, some of our subjects are stand-alone actors whose link to an ideal cause is at best tenuous. Ferrero (2006) and Wintrobe (2006a, 2006b) focus on the interaction of selfish individuals with a group; Azam (2005), by contrast, focuses on the individual's inter-generational altruism toward kin or fellow community members. Both the group and the altruism are conspicuously absent from the Herostratic context.

A lone exception in this literature is a paper by Eswaran and Neary (2015), which models terrorist actions in the framework of the economics of identity captured by the 
contrast between "Us" and "Them". Social identity makes individual terrorist activities possible without explicit coordination, thus allowing analysis of decentralized terrorism (including so-called "lone wolf" terrorism) that is not organized or state- or group-sponsored. In their model, both the number of active terrorists and the intensity of individual terrorist effort increase not only in individuals' altruism toward the in-group but also in their spite toward the out-group; furthermore, while in-group altruism is found to magnify the intensity of terrorist actions, it is out-group spite that is essential for the action to exist in the first place. Although their model is set in the context of a conflict between two countries for the control of a resource, and is not restricted to suicide terrorism, this key role of spite for out-group members, including a wanton disregard for their lives, captures an aspect of the rational pursuit of "evil" (although it is regarded as patriotic and benign by in-group members) that the present paper seeks to address.

The other research topic that is germane to ours is lone-wolf terrorism, where economic analysis has been applied to the terrorists' choice of methods of attack (Phillips, 2011). In particular, Phillips and Pohl (2014), using prospect theory that incorporates dependence on a reference point, study the behavior of "copycat" terrorists that seek to emulate or surpass the achievement of a predecessor taken as a reference point and compute sets of preference orderings over attack methods from an extensive dataset on international terrorism. Even though many lone wolves have not been suicides, this paper stands out as the only instance to date that addresses a competition among individual agents in which, whatever the underlying ideology, inflicting a target level of injuries and fatalities is the agent's purpose. This behavior is, however, simply assumed, not explained or grounded in utility theory. We make a step back to the foundations and provide a general theoretical framework that locates the lone wolf's actions within a range of possible behaviors while not necessarily 
requiring that the agent is a "terrorist" as normally understood (see the discussion of school shootings in a later subsection).

Perhaps the predecessor to which the present paper is most directly related is Ferrero (2013), which explicitly introduces a value of being lovingly remembered after death into the utility function and models a "contract for martyrdom" between some individuals and a sponsoring organization, which provides a cult of martyrs to fulfill its side of the contract. The individual is motivated to sacrifice his life by the expectation of the cult that will keep his name and deeds alive; however, a cult will be granted to all who deserve it so that there is no competition among agents to outdo one another to secure one's worship. The present paper turns this approach on its head: our Herostratic agents do value survival in their followers' memory after death but try to achieve this by pursuing infamy for their heinous deeds instead of fame for their worthy deeds; there is no sponsoring organization but a cult of sorts nevertheless does develop and is anticipated at the time of action; but since the "cult" here is upheld by (some section of ) society itself, notoriety (i.e. making headlines) becomes the key factor and our agents are driven to compete and try to match and surpass one another's achievements if they are not soon to be forgotten.

\section{The Herostratos syndrome}

\subsection{Some history}

In this paper, we borrow the phrase "Herostratos syndrome" from Borowitz (2005), which is the first comprehensive study of the topic. Following his account (ibid., chap. 1), in $356 \mathrm{BC}$ a man named Herostratos burned to ashes the great temple of Artemis at Ephesus, a Greek city in today's Turkey. The temple was celebrated as one of the Seven Wonders of the ancient world. Herostratos did not try to escape and he was then tortured and executed by the city authorities. The ancient sources provide no information on the perpetrator or the motive 
of his act except that he avowedly did it so that his name may live forever after on account of the enormity of his crime. Precisely to defeat his purpose, the city authorities also decreed that his name shall never be mentioned so as to erase it from the historical record. This type of punishment for the most grievous offenses against the state was widespread in the ancient world and known in Roman law as "condemnation of memory" (damnatio memoriae). This memory ban, however, was soon flouted by the ancient authors themselves, through whose writings Herostratos' name and deed have come down to us via a long tradition of literary and philosophical elaboration.

While the memory ban as a policy tool deserves further discussion in a later section of this paper, it is interesting now to zoom in on the motives of Herostratos' action. The reason why his name was not forgotten but handed down to history - and in this sense, his endeavor proved to be a resounding success - is because the ancient writers saw it as a paragon of a perverted quest for fame and immortality when joined to a perception of one's mediocrity and failure. The ancient world had a lively cult of heroes - men whose name long outlived them on account of their virtue and worthy deeds. If a man - so reasoned the ancient commentators - is desperate for fame but is too base ever to hope to achieve it by heroic acts, he may try and satisfy his craving by uncommonly heinous acts. They do not mention any kind of emulation or competition for infamy taking place in their time; the Roman historian Valerius Maximus, however, noted that a singular innovation of Herostratos' act was that by targeting an iconic monument - or, in other similar instances, by killing a famous man - the target's celebrity would redound to the perpetrator, who would then wear it as his new identity. So Herostratos not only established a classic topic for intellectual argument but set a pattern that, though unknowingly, would be followed through the centuries to this day. 
Borowitz (2005) provides many historical examples of attacks where the quest for infamy might credibly be diagnosed as the main objective pursued by the perpetrators, ${ }^{2}$ as well as an extensive discussion of various strands of literature. He distinguishes first the "destroyers" from the "killers" in his narratives. However, he then notes that 9/11 was a remarkable synthesis of these two types of attacks, where the highly symbolic Twin Towers and four large aircrafts were destroyed, while about 3,000 ordinary citizens were killed. In chapter 5, Borowitz (2005) discusses the pros and cons of identifying a Herostratic dimension in the 9/11 attacks citing several sources. Other examples of destruction of highly symbolic monuments for the sake of attracting world-wide publicity include the destruction of the Buddhas of Bamiyan in Afghanistan by the Taliban in March 2001 and the destruction of the 2000-year old temple of Bel in Palmyra by ISIS in September 2015. The latter's presentation of the resulting ruins in their English language magazine Dabiq leaves no doubt about the quest for infamy thus pursued. These three spectacular destructions got a world-wide echo in the popular media and the cyberspace and very quickly turned Osama Bin Laden into a household name, as well as to a lesser extent the Taliban and ISIS.

Among the killer attacks described by Borowitz (2005), the rising phenomenon of school shootings is given special attention. It seems to be related to the instant fame that their perpetrators get thanks to the mass media and the cyberspace.

\subsection{The school shooting epidemic}

Massacres on American school premises by current or former students were relatively rare before the 1990s when they picked up and dramatically escalated in number and level of violence, leading mass media and scholars to speak of an epidemic (Larkin, 2009; Rocque,

\footnotetext{
${ }^{2}$ In an interesting variation, Bartlett (1993) shows that such a quest was common among the pagan Slav tribes of North-Eastern Europe in the Middle Ages, as the funeral orations of their prestigious members were praising their most infamous deeds.
} 
2012; Agnich, 2015). The infamous shooting at Columbine High School in 1999 marked a turning point, providing an example and a "cultural script" for many subsequent followers to emulate. After Columbine, not only have actual school shootings multiplied but large and increasing numbers of planned shootings have been foiled by police or aborted for some other reasons, so that the total number of youths who set their minds on firing a weapon at their classmates has become an order of magnitude greater than in previous periods. Moreover, after Columbine, the phenomenon - previously almost exclusively American - has gone global, involving schools all over the world. A recent example is the deadly attack on a Swedish school carried out in October 2015 by a young man with Nazi sympathies but no links to any far-right organization. This was certainly a first: he wore a Darth Vader-style mask, cape, and helmet and, fittingly, his weapon of choice was a sword (Crouch, 2015). Finally, the context itself has begun to change: rampage killers have been targeting church groups, shopping malls, and gyms among other venues. Scholars and policy-makers have been struggling to understand the why and how of such epidemic.

Observers have been baffled by the fact that, beyond being young, mostly white (in the U.S. at least), and overwhelmingly male, there is a dearth of common traits that could help build a profile of the typical perpetrator. Some perpetrators were psychotic, or were diagnosed mental disorders after the fact, but many were apparently normal kids. Some came from broken families or were physically or psychologically abused by parents or others, but many had grown up in functioning families with loving parents. Many had a history of social isolation and rejection and/or bullying by their peers, but some did not or were themselves bullies or were quite popular among their peers, and in any case their shooting rampage went well beyond the supposed offenders, targeting fellow students and school staff basically at random. So a troubled mind, a troubled background, and a quest for revenge, while undoubtedly a factor, seem insufficient to explain the shootings. What is more, troubled, 
angry boys have always existed without engaging in any such behavior, so listing these and other risk factors cannot begin to account for the modernity of the phenomenon and for its increasing rate of occurrence.

A suicidal intention, whether by killing oneself or by provoking the police to shoot the perpetrator (so-called "suicide by cop"), has often been carried out or at least attempted; even when not, the shooters often did not try to run but were prepared to face the consequences of their acts, ranging from capital punishment through life imprisonment to long periods of detention or other legal restraint. Explicit evidence for a suicidal intention, in addition to observed behavior, is often provided by the suicide notes left or the internet messages disseminated by the perpetrators prior to acting. This feature is reminiscent, on the one hand, of Islamic suicide terrorists in the Middle East and elsewhere, who typically record a video before immolating themselves (Lankford and Hakim, 2011, Nesser, 2015), and, on the other hand, of "suicide with hostile intent", a ritualized procedure that was widespread across ancient Mediterranean cultures and in recent pre-industrial cultures around the world (Preti, 2008; see also the literature cited therein). However, suicide terrorists are typically affiliated to an organization which directs them and provides a political cause for their martyrdom, while ancient hostile suicides were soldiers engaged in a military operation against an enemy and modern ethnographers' suicides are intent on exacting revenge on specific individuals who wronged them. By contrast, school shooters are loners, they target civilians, and given that they engage in mass slaughter, the revenge motive behind their actions is, as we have seen, problematic. As to the political motive, Larkin (2009) argues that while the motivations of pre-Columbine school shooters were personal and focused on petty grievances, they were raised to an overtly political status by the Columbine killers, who stated in their videotapes that they wanted to "kick-start a revolution" among the victimized and downtrodden students of the world - a "manifesto" that apparently influenced subsequent shooters. Still, calling 
such a motive "political", when set against the motives of fighters, revolutionaries, and terrorists of all stripes, seems a long stretch, and what is more, targeting random fellow students seems distinctly inconsistent with the "revolutionary" motive as stated.

A key to solving the puzzle may be found in the exemplary, trend-setting nature of the Columbine event itself. As Larkin $(2009,1312)$ writes, "the Columbine rampage has become a cultural script for many subsequent rampage shooters. For some, it was a record to be exceeded ....; for others, it was an incitement ....; for others, it was emulated in their own rampages ...; for still others, it was a tradition to be honored in their own attacks." Even if only four shooters (two in the U.S. and two in Germany) managed to actually outdo Columbine's death toll, the evidence of explicit imitation, referencing, and emulation of Columbine by subsequent shooters - often taken as an instance of "copycat killing" - is overwhelming for both completed and failed or thwarted school attacks in the United States, as well as for many of those in other countries. "The body count ..... exists primarily as a method of generating media attention", which post-Columbine rampage shooters have attempted to influence rather than merely be influenced by them (ibid., 1322). This reveals the fundamental motive of post-Columbine killers: killing for notoriety. To these boys, "payback consists of killing convenient targets, making a statement, and dying in a blaze of glory" (ibid., 1323). Similarly, Lankford and Hakim $(2011,105)$ identify the drive to seek fame and glory as one of the most important similarities between rampage shooters and Palestinian suicide bombers; in both cases, this is a reaction to a condition where - albeit for different environmental reasons - the subjects suffer from low self-esteem. In one of the most revealing pieces of circumstantial evidence, as his foster mother reported, mall shooter Robert Hawkins wrote in his suicide note that "he was a piece of shit all of his life and now he'll be famous" (ibid.). 
In an insightful essay on the school shooting epidemic, Gladwell (2015) brings in sociologist Mark Granovetter's well-known model of collective behavior (Granovetter, 1978), in which individuals' decision to participate in a collective movement, such as a riot, is driven by their thresholds - defined as the number of people who need to be doing something before one agrees to join them. Riots are started by firebrands - individuals with a threshold of zero - and then grow by drawing in people with successively higher thresholds - up to people who would not normally even think of doing any such thing until and unless sufficiently many others were already doing it. Gladwell suggests that the school-shooting epidemic is like a slow-motion, evolving riot, in which each new participant's action must be understood in reaction to previous participants. He reviews the evidence of the progression of the "riot" from the early psychopaths - the low-threshold instigators - to ever-higher-threshold boys who more and more identify with the school-shooting tradition and celebrate the cult of its heroes - the Columbine shooters. Concluding his discussion, Gladwell writes: "the riot has now engulfed the boys who were once content to play with chemistry sets in the basement. The problem is not that there is an endless supply of deeply disturbed young men who are willing to contemplate horrific acts. It's worse. It's that young men no longer need to be deeply disturbed to contemplate horrific acts."

The foregoing picture fits the pattern of Herostratic competition very well. The killers are engaged in a quest for notoriety and compete with one another over the increasing (intended) lethality of their attacks; the more recent recruits would not have started the movement but are ready to join the crowd. This Herostratic interpretation of the schoolshooting epidemic, however, carries a disturbing policy implication that is the opposite of the conventional wisdom on prevention and deterrence. This directs attention to early, preventive detection of possible candidates: the psychological or sociological models of cumulative risk factor, which profile disturbed males who are social outcasts with a troubled family 
background, a lust for revenge, and easy access to firearms (Rocque, 2012). If, however, we interpret the epidemic as a cumulative movement that slowly evolves through time and therefore the Nash equilibrium (which will be defined and analyzed in section 4) as a condition where no new entrant is willing to strike, the epidemic as heretofore seen will at some point begin to lose momentum and taper off even without any special counter-measures - the notoriety gains at the margin will no longer be worth sacrificing one's life. Instead, attention should focus where the epidemic has not yet reached and therefore the potential gains from starting are enormous. One characteristic stands out: gender. The women's representation in the epidemic has been so far negligible. If only a woman arises who is so deranged as to be willing to start out, we may be set to witness a fresh wave of school shootings with a vast unexplored territory to cover.

\subsection{Mohamed Merah's Jihadist school shooting}

Mohamed Merah is a good example of a quasi-lone wolf whose main contacts with the world of Jihad was via the Internet. His story is well known because he took the time to spell out all the details in his conversation with the police while he was trapped in his flat in Toulouse (Moutouh, 2013). On day one, Sunday, March 11, Merah met a French Muslim soldier in Toulouse, pretending to be interested in buying the scooter the latter had advertised for sale. He eventually shot him dead. On day two, four days later, Merah took his own scooter to ride $50 \mathrm{~km}$ north to Montauban, where he shot three soldiers near the barracks they had just left to go on leave, as they were about to draw cash from an ATM machine. Two where French Muslims, while the third one was from the French Antilles. On day three, on March 19, Merah tried to trap another French soldier, but the plan fell through. Disappointed and idle, he then decided to go to the Jewish school Ozar Hatorah. There, he first started to shoot in the street, killing a teacher called Jonathan Sandler and one of his sons, and then 
entered the school where he killed Sandler's second son and a little girl. On his way out, he shot father and son again in the street, as they were still moving. The GoPro camera worn by Merah on the three occasions produced videos that ended up on various Jihadist websites.

The first two days of killing had a clear strategic motive within a Jihadist framework, aimed at punishing collaborationist Muslim soldiers with a view to deepening the gap between the Muslim community and the French society at large. Still, the improvised attack on the Jewish school had a much stronger media impact, as it attracted the Minister of Interior, Claude Guéant, the President, Nicolas Sarkozy, as well as Benyamin Netanyahu who came to share the sorrow of the parents and children of the Ozar Hatorah school. In a nutshell, Jihad does not pay off to make a name for oneself, while an anti-Semitic school shooting makes you hit the headlines instantly. This set the standards for subsequent Muslim killers, who focused on killing Jews and artists more than on the Jihadist agenda against soldiers.

The Merah case can be taken as the paragon of the Herostratic contract that ISIS is offering its followers in Europe. By endorsing and encouraging such actions through the implicit promise of wide publicity in the cyberspace, ISIS is trading off the harm it inflicts (at least in the short run) on the Palestinian cause by killing Jews in Europe against the fact that the latter offers the killer a much higher probability of getting instant stardom, so that allowing the killing of European Jews as an eligible Jihadist action will attract many more recruits than banning it. That is, ISIS is leveraging the Herostratos syndrome as a channel for attracting cheap cannon fodder in support of suicide bombings and mass massacres in Syria and Iraq - religion seems not to be powerful enough to attract enough fighters. So the Palestinians are sacrificed for the sake of the more general Sunni Muslim cause in the Middle East - hence the title of this paper. In this view, there is more than Jihad in the current wave of private mass killings in Europe, and the Merah pattern turns out to be much more similar to the purely Herostratic school shootings discussed above than is generally recognized. 
The following model aims at better understanding how the Herostratic motive can play a dominant part in shaping the equilibrium of a killers' game.

\section{A rational choice model of Herostratic attacks}

The aim of this section is to provide a model of hybrid killers whose motivations can encompass the pure Herostratos syndrome case as well as more general ones taking into account the negative spillovers that run counter to their proclaimed cause. It first focuses on the individual motivations to perform a suicide lethal attack before analyzing the Nash equilibrium number of such attacks.

\subsection{Micro-foundations}

Assume that there is a continuum of heterogeneous potential killers $k \in[0, \infty[$ who would derive the following utility from perpetrating a suicide attack:

$$
U(\theta(k), \beta(k), n, \psi, \alpha, \mu)=\max _{q} \theta(k) v(n, q, \psi)-\alpha c(q)-\beta(k) \mu m(n),
$$

where $v(n, q, \psi) \geq 0$ is a continuously differentiable function that measures the expected impact on public opinion of perpetrating a given type of attack when $n$ such attacks are simultaneously perpetrated, and the quality of attack $q$ is chosen. Such "quality" measures the (intended) intensity of the attack in terms of lethality, number of potential victims, especially loathsome choice of targets or of weapons (such as the children sent out as human bombs by Boko Haram), and the like. The shift parameter $\psi$ could be called the publicity of the attack: it captures the media environment that will bring the killer's name to the headlines and the sensitivity of public opinion to this kind of news; it can also be used as a policy tool to influence this. The function $v(n, q, \psi)$ thus captures the "Herostratic contract" described 
above whereby infamous arsonists or killers have a high probability of being remembered for decades or even centuries, in a sort of macabre hall of fame. This expected impact is valued at the subjective price $\theta(k)$ by potential killer $k$. This subjective price measures the Herostratic leanings of individual $k$, and we assume that it is a continuously differentiable function that ranks, by convention, potential killers by decreasing values of $\theta(k)$, i.e., $\theta^{\prime}(k)<0$

Assuming that only suicide attacks are taking place within the period under study, and that all attackers actually die, entails that the number of attacks and the number of killers are the same. This definition of suicide attacks must be understood broadly so as to include all the cases where the killer dies in the end, whether by his own means or killed by the police after his action as happened to Mohamed Merah in Toulouse. Pape (2006) uses also a similarly broad definition of suicide attacks. The probability of the agent's actually dying, whether by voluntary suicide or "suicide by cops", could even be less than one provided he is subsequently apprehended or otherwise unable or unwilling to act again. The only point that matters is that the number of attacks and the number of killers are the same in this model, for the sake of simplicity.

The number of attacks performed by the $n$ killers has a potentially ambiguous effect on the public's collective memory. On the one hand, repeated attacks of a given type increase the public's sensitivity to these attacks by creating an enhanced level of anxiety that amplifies their impact relative to an isolated one, thus creating a kind of addiction. On the other hand, beyond a point, the public might lose its interest for this type of "déjà vu" attacks. This potential ambiguity is captured by assuming a bell-shaped effect of $n$ on $v(n, q, \psi)$, allowing for an interior maximum. In contrast, the attack's quality $q$ has a monotonically positive effect, with diminishing marginal returns, on its expected impact $v$ (.). The cost of the attack $\alpha c(q) \geq 0$ is assumed to be an increasing and convex function of its quality $q$. This cost may 
include both the direct financial cost and the time, skill, and effort costs of planning, organizing, and procuring the necessary material for the attack, all of which would naturally be increasing with its quality (recalling that the latter is a gauge of how daring, outrageous, massive, and unmatched the attack is) irrespective of whether they are borne by the attacker himself or by some organization behind him. The positive parameter $\alpha$ is a shift parameter reflecting the security environment in which the potential killer operates, e.g., the effectiveness of the legal apparatus restricting the purchase of firearms, whether legally or illegally, and its degree of enforcement. Thus, defining $\tilde{n}$ as the maximum of $v(n, q, \psi)$ with respect to $n$, we have:

$$
\operatorname{Sign} \frac{\partial v}{\partial n}=\operatorname{Sign}(\tilde{n}-n), \frac{\partial v}{\partial q}>0, \frac{\partial^{2} v}{\partial q^{2}} \leq 0, \frac{\partial v}{\partial \psi}>0, c^{\prime}(q)>0, c^{\prime \prime}(q)>0 .
$$

Moreover, utility function (1) also includes $\mu m(n), m^{\prime}(n)>0$, where $\mu>0$ is another shift parameter. This function captures the negative externality, or unintended side effects, entailed by the attacks, which are obviously increasing in the number of attacks. For example, repeated spectacular killings of Jews in Europe increase the migration of other Jews to Israel, a phenomenon that furthers the interests of Zionists while being detrimental to Palestinians. Similarly, a lot of the killing entailed by suicide bombing attacks falls on people whose interest is supposed to be served by the attacks. These negative spillovers, or "collateral damage", are valued at the subjective price $\beta(k)$ by potential killer $k$. Hence, a high value of $\beta(k)$ might describe an "ideological" killer, i.e. one with a high degree of commitment to a cause that might be damaged by the attack. However, given our ordering of $k$, implying $\theta^{\prime}(k)<0$, there is no natural way to sign the derivative $\beta^{\prime}(k)-$ a fact that will be important to the structure of the equilibrium. 
Table 1 summarizes the types of potential killers that can be described by this utility function by combining high or low values of $\{\theta(k), \beta(k)\}$.

Table 1: Taxonomy of Potential Killers

\begin{tabular}{|l|l|l|}
\hline & High $\boldsymbol{\beta}(\boldsymbol{k})$ & Low $\boldsymbol{\beta}(\boldsymbol{k})$ \\
\hline High $\boldsymbol{\theta}(\boldsymbol{k})$ & Passionate Borderline & Herostratic Killer \\
\hline Low $\boldsymbol{\theta}(\boldsymbol{k})$ & Hands-Off Sympathizer & Anomic Borderline \\
\hline
\end{tabular}

\subsection{The Herostratic competition}

The borderline types are the most interesting ones from the policy point of view. These are the potential killers that small changes in incentives could motivate to cross the line one way or the other. The Nash equilibrium of the game analyzed below determines who does perpetrate an attack and who refrains from it, and thus the equilibrium number of attacks $n$. The latter in turn determines the equilibrium quality $q$ of the attacks which is governed by the function described in proposition 1.

Proposition 1: The chosen quality of the attack may be written as:

$$
q^{*}=q(\theta(k), n, \psi, \alpha), \operatorname{Sign} \frac{\partial q^{*}}{\partial n}=\operatorname{Sign}(\tilde{n}-n), \frac{\partial q^{*}}{\partial \theta(k)}>0, \frac{\partial q^{*}}{\partial \psi}>0 \text { and } \frac{\partial q^{*}}{\partial \alpha}<0
$$

if:

$\operatorname{Sign} \frac{\partial^{2} v}{\partial q \partial n}=\operatorname{Sign} \frac{\partial v}{\partial n}$ and $\frac{\partial^{2} v}{\partial q \partial \psi}>0$

Proof: From the first-order condition $\theta(k) \partial v / \partial q=\alpha c^{\prime}\left(q^{*}\right)$, one can compute the total differential and rearrange the terms to get: 
$d q^{*}=\frac{\frac{\partial v}{\partial q} d \theta(k)+\theta(k)\left(\frac{\partial^{2} v}{\partial q \partial n} d n+\frac{\partial^{2} v}{\partial q \partial \psi} d \psi\right)-c^{\prime}\left(q^{*}\right) d \alpha}{\alpha c^{\prime \prime}\left(q^{*}\right)-\theta(k) \partial^{2} v / \partial q^{2}}$.

Then, the partial derivatives in (3) can be read off (5).

Condition (4) is a very natural assumption saying that $v(n, q, \psi)$ becomes steeper as a function of $q$ when it shifts upwards as $n$ or $\psi$ change and flatter when it shifts downwards. Then, it gives to the quality of attack a realistic tournament property within a certain range, namely that the Herostratic killer will invest more in the quality of his attack, the larger the number of attacks of the same type expected to take place in the same period. This is nicely illustrated by Mehdi Nemmouche who declared: "Je vais faire cinq fois Merah au 14 juillet" (I will do five times Merah on French National Day, translation by JPA). It is then extremely significant that Nemmouche felt like competing with Merah on the sensational but strategically inept Jew-killing front, while he did not attempt any more strategic moves like killing French Muslim soldiers as did Merah in Montauban as a way of deterring young French Muslims from getting integrated in their society and of inciting possibly some of them to join the Global Jihad instead.

Lastly, potential killers are facing an opportunity cost of perpetrating a suicide attack captured here by a value of life, which we assume constant for all, $L(k)=\lambda>0, \forall k$, for simplicity. Then their decision rule is naturally that potential killer $k$ will perpetrate the suicide attack if $U(\theta(k), \beta(k), n, \psi, \alpha, \mu)>\lambda$ and will refrain from it otherwise. ${ }^{3}$ This realistically assumes that there is free entry in the killing activity, thus ruling out pre-emptive

\footnotetext{
${ }^{3}$ In an interesting contribution to this line of thinking, Apolte (2017) argues that an individual's decision to embark on a suicide-killing path may be time-inconsistent and addresses this commitment problem by postulating different profiles of lifetime reservation utility. He finds that only a person beset by a serious "burden of life" will fulfill his "contract with himself" and carry out the suicidal attack as a "lone wolf", while those not so burdened will need an external enforcement mechanism such as one provided by a terrorist organization. The incentive role played by Herostratic competition among agents is, however, not addressed by his model.
} 
interventions of the police that could take people into custody just on the basis of their profiling as "dangerous potential killers", e.g., because the police cannot identify each individual's preference parameters $\{\theta(k), \beta(k)\}$. As this decision to kill depends on $n$, each potential killer must work out the equilibrium number of attacks in order to make his own attack decision. We use a simple simultaneous-move equilibrium framework to analyze the resulting outcome.

\subsection{The equilibrium number of attacks in the Herostratic equilibrium}

For the sake of simplicity, let us rule out any kind of direct coordination among the potential killers and thus use the standard simultaneous-move Nash equilibrium concept. This also neglects the sequential occurrence of attacks that can be observed in reality, often bunched in time, for the sake of simplicity. Moreover, one might argue that the Herostratic killers want to be remembered for a very long time, as Herostratos himself who is still cited more than two millennia after his arson. Then, a lag of a few weeks or a few months between successive Herostratic attacks is unlikely to matter for their long-run reputation impacts. Similarly, let us assume that $\beta(k)$ is continuously differentiable. This imposes some constraint on the type of heterogeneity among potential killers that can be handled by the model. It entails that people who have similar preferences regarding the Herostratic contract also have similar preferences regarding the negative spillovers of their acts, irrespective of whether they change in the same or the opposite direction. Then, define the killer's (subjective) profit function as:

$$
\pi(k, n, \psi, \alpha, \mu, \lambda) \equiv U(\theta(k), \beta(k), n, \psi, \alpha, \mu)-\lambda .
$$

This function is continuously differentiable in $k, n, \psi, \alpha, \mu$ and $\lambda$. Then, the decision rule defined above may also be written as: potential killer $k$ will perpetrate the suicide attack 
if $\pi(k, n, \psi, \alpha, \mu, \lambda) \geq 0$ and will refrain from it otherwise. Because $n$ is endogenously determined in equilibrium, the latter is in fact determining the identity of the players who will commit an attack and of those who will refrain from it.

Let us now define the Herostratic equilibrium of this game as a Nash equilibrium where $\theta(k)$ is the key determinant of the killers' identities, i.e., where the $n$ active killers are the ones with the largest values of $\theta(k)$.

Definition 1: A Herostratic equilibrium of this game is a Nash equilibrium where $n^{*}=k^{*}$.

Proposition 2 gives a familiar-looking set of sufficient conditions for such a simple and meaningful Nash equilibrium to exist in this game.

Proposition 2: There exists a unique Herostratic equilibrium of this game where $n^{*}=k^{*}$ and $\pi\left(k^{*}, n^{*}, \psi, \alpha, \mu, \lambda\right)=0$ if the following four conditions hold:

(i) Single Crossing from Above:

$\theta^{\prime}(k) v\left(n, q^{*}, \psi\right)<\beta^{\prime}(k) \mu m(n), \forall k, \forall n$

(ii) Bounded Addiction:

$$
\frac{\partial v}{\partial n}<\frac{\beta(k) \mu m^{\prime}(n)-\left[\theta^{\prime}(k) v\left(n, q^{*}, \psi\right)-\beta^{\prime}(k) \mu m(n)\right]}{\theta(k)}, \forall k, \forall n
$$

(iii) Rare-Killing Allure:

$\lim _{k \rightarrow 0, n \rightarrow 0} \pi(k, n, \psi, \alpha, \mu, \lambda)>0, \forall \psi$

and:

(iv) Asymptotic Innocence:

$\lim _{k \rightarrow \infty} \pi(k, n, \psi, \alpha, \mu, \lambda)<0, \forall n$ and $\forall \psi$ 
Condition (7) ensures that for any given value of $\{n, \psi, \alpha, \mu\}, \pi(k, n, \psi, \alpha, \mu, \lambda)=0$ has at most one solution. It restricts the admissible range of correlations across $k \mathrm{~s}$ between the values that they attach to the Herostratic impact of their attacks and to the negative spillovers that they entail. The condition is obviously satisfied if $\beta^{\prime}(k) \geq 0$, i.e. if people with the strongest Herostratic tastes have the lowest valuation of collateral damage; in this case, as $k$ increases we move diagonally from Herostratic killer to Hands-off sympathizer in Table 1. By contrast, condition (7) may or may not hold if $\beta^{\prime}(k)<0$. It might fail for example if people who attach a slightly lower value to the Herostratic impact of an attack also care significantly less for the latter's negative spillovers. In that case, the utility derived from killing might always be strictly above the value of life for all the potential killers who would then all go for it if (9) also held. Moreover, failure of (7) to hold could entail that killers could belong to several disjoint intervals of the $k$ line (see Appendix A), for example that beside people with the strongest Herostratic leanings another set of people with very weak such leanings would engage in killing, while those with interim values would refrain from killing. Conditions (7) and (8) jointly rule this out and give the equilibrium analyzed here a welcome monotonicity property for the sake of interpretation. Condition (8) requires that the Herostratic impact of the attacks does not increase too strongly with their number, for example because the public gets affected even by the first isolated attack. Notice that the term in square brackets is negative by the single-crossing condition, so that the right-hand side of (8) is always positive. Hence, (8) might hold even in the case of a pure Herostratic killer like Andreas Lubitz, the pilot who crashed a Germanwings flight in March 2015, probably was, with $\beta(k)=0$. (See Appendix A for proof that failure of (8) to hold might imply multiple equilibria.) Hence, (7), (8), (9) and (10) jointly entail that a unique, interior Nash equilibrium exists where people 
with strong Herostratic leanings will engage in killing while people with weaker ones do not cross that line.

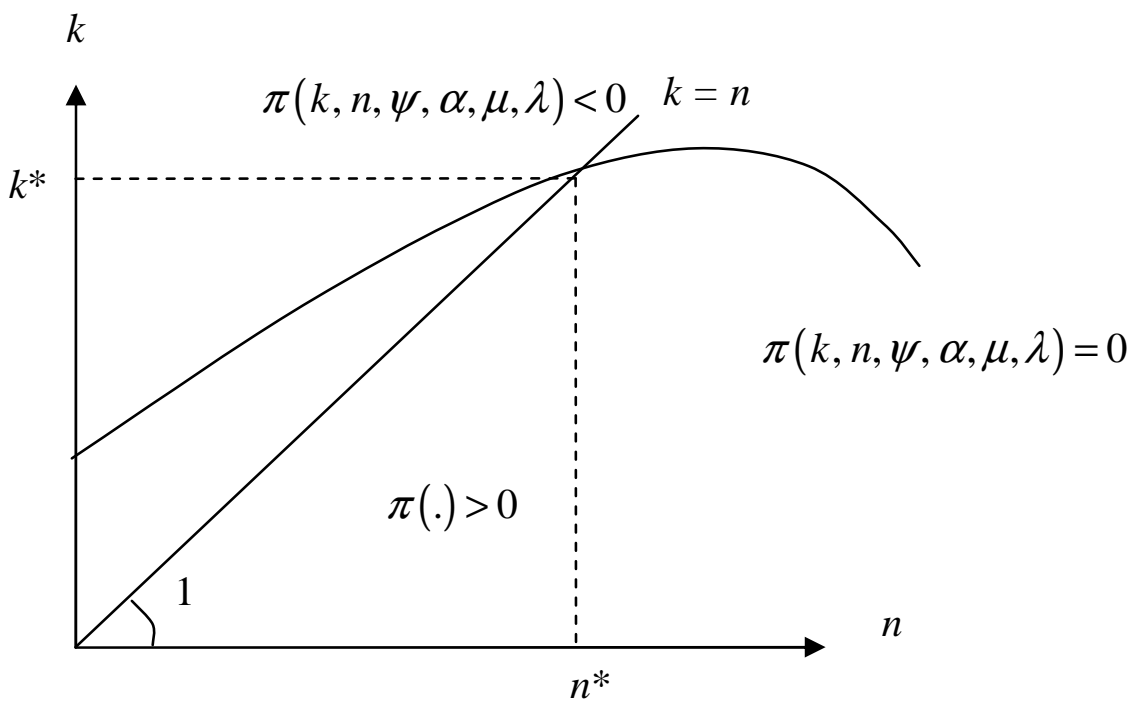

Figure 1: The Nash equilibrium of Proposition 2

Figure 1 offers some intuition about this Nash equilibrium. The bell-shaped curve represents the locus of the $\{k, n\}$ pairs such that $\pi(k, n, \psi, \alpha, \mu, \lambda)=0$. It is straightforward to check that this curve reaches a maximum when:

$$
\frac{\partial v}{\partial n}=\frac{\beta(k) \mu m^{\prime}(n)}{\theta(k)}>0,
$$

so this occurs when $n<\tilde{n}$, i.e. the $v$ (.) function is still increasing in $n$ (see (2)). All the $\{k, n\}$ pairs located above this locus are such that $\pi(k, n, \psi, \alpha, \mu, \lambda)<0$ while all those below it have $\pi(k, n, \psi, \alpha, \mu, \lambda)>0$. The Nash equilibrium described in Proposition 2 is found where this locus intersects the $45^{\circ}$ line. All the active killers are found on or below this locus while all the potential killers whose $k$ lies above this locus have $\pi(k, n, \psi, \alpha, \mu, \lambda)<0$ and thus refrain from killing. The equilibrium depicted in Figure 1 occurs when $n<\tilde{n}$ and is such that 
the Herostratic tournament described in Proposition 1 is in full gear, as the quality of attacks is increasing with their number. This equilibrium is not a symmetric one, as each killer will choose a quality level $q^{*}\left(\theta(k), n^{*}, \alpha, \psi\right)$ that depends on the idiosyncratic subjective price $\theta(k)$ as shown by Proposition 1. The school shootings epidemic, described in a previous section, fits this picture particularly well, with the quality of attacks increasing with their (cumulative) number. The resulting increase in notoriety and in the subjective profit from the attacks as the number of attacks/participants grows nicely captures the bandwagon effect that lures in people with increasing participation thresholds à la Granovetter.

The $k=n$ line may in fact intersect the $\pi(k, n, \psi, \alpha, \mu, \lambda)=0$ locus on either side of $\tilde{n}$. Then $n^{*}>\tilde{n}$ may only occur if this intersection is found in the downward-sloping part of the locus, and far enough from its maximum. In this case, the quality of the attacks is decreasing with their number. Figure 2 illustrates a case where this might happen.

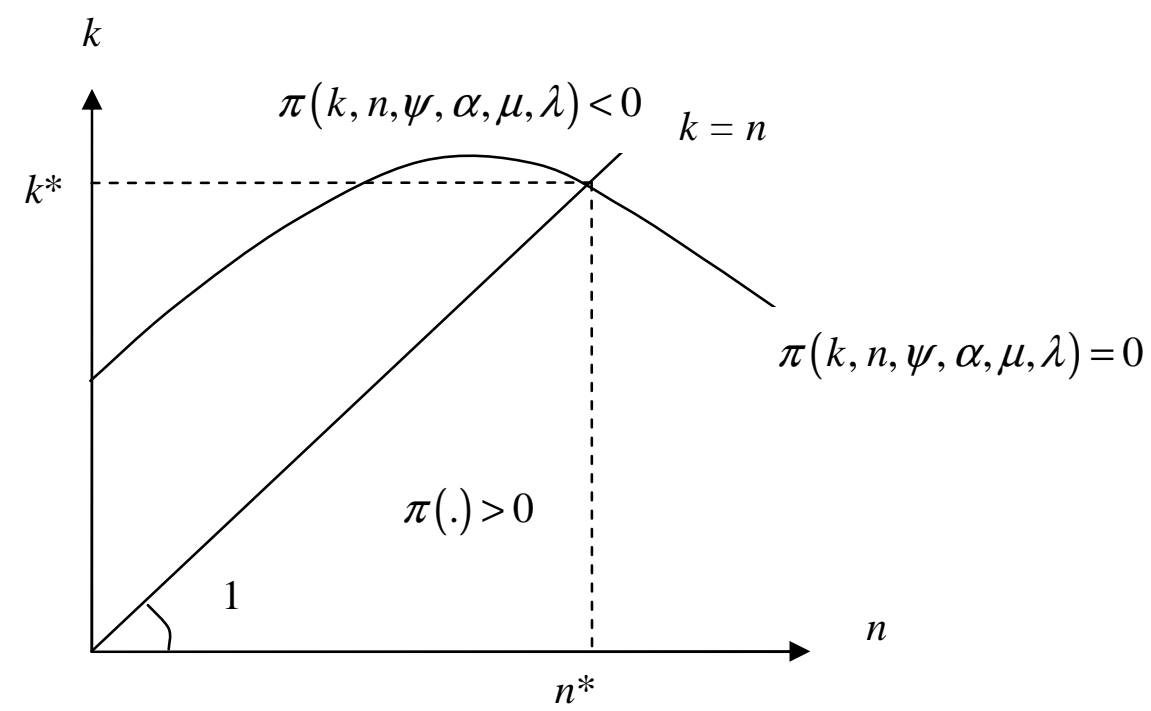

Figure 2: A case where $n^{*}$ might be above $\tilde{n}$

Appendix A shows that the sufficient conditions set out by Proposition 2 are not necessary to produce a meaningful Nash equilibrium whose properties can be analyzed 
graphically. However, the monotonicity of the equilibrium described by Proposition 2 and Figures 1 and 2 makes it simpler and more appealing than those with multiple equilibria, with or without disjoint sets of killers. This is why we use the well-behaved case to derive some policy implications in the next section; to do that, we first discuss the comparative statics properties of the Herostratic equilibrium.

\section{Some policy implications}

Public policies to counter the Herostratic threat in this model can work through four channels: (i) by affecting directly the impact of the attack on public opinion $(\psi)$, (ii) by affecting its opportunity cost $(\lambda)$, (iii) by affecting the cost of choosing a more spectacular attack $(\alpha)$, or (iv) by affecting the perceived cost of collateral damage $(\mu)$. As $n^{*}$ and $q^{*}$ are jointly determined, the four policy tools affect both outcomes simultaneously. Figures 1 and 2 can be used to work out their impacts on $n^{*}$. A look at equations (1) and (6) shows that an increase in $\lambda$, in $\alpha$, or in $\mu$, and a fall in $\psi$, would shift down the $\pi(k, n, \psi, \alpha, \mu, \lambda)=0$ locus along the $k=n$ line and drive some potential killers - the borderline ones - into inaction, irrespective of whether we are in a Figure 1 or Figure 2 type of Nash equilibrium. To confirm this, Appendix B gives the comparative statics derivatives. Notice that conditions (7) and (8) ensure a continuous response of $n^{*}$, ruling out the discontinuous jumps that might otherwise arise (discussed in Appendix A).

\subsection{Limitations of cost-oriented policies}

Work on $\lambda$ is likely to be the least cost-effective: it basically affects reservation utility and tries to provide people with better alternatives than becoming a suicide terrorist - that is, it seeks to influence individuals' participation constraint. So economic growth, better-paid jobs, and the availability of social services on a non-discriminatory basis can certainly 
undercut the appeal of the Herostratic contract (see Azam, 2012). By the same token, a general improvement in Law and Order, even if not specifically targeted at the Herostratic crimes, would have a similar effect by providing a safer social environment. This is Berman's (2009) well-known suggestion to drain the water where terrorist organizations fish for recruits; a policy of increasing $\lambda$ would be its counterpart in the world considered in this paper where there exist no organizations but only individuals. With or without organizations, however, such a policy promises to be an enormously costly, long drawn-out operation as it must confront a huge pool of potential recruits without knowing who they are in advance of action. Improving the social lot of all the Muslim residents of Europe, while worthwhile in itself, does not look very much on target. The approach initiated by Azam (2005), Wintrobe (2006), Ferrero $(2006,2013)$, and pursued further in this paper, seeks to address individuals' incentives to act, aiming at certain types of individuals and trying to change their perceived costs and benefits from action.

If the cost of action $\alpha c(q)$ increases parametrically, for example because the government increases $\alpha$ by making planning and implementation more difficult, $q^{*}$ will fall by Proposition 1 and the actions undertaken will be less heinous than before. This could be achieved either through tighter gun control or by disrupting more systematically Jihadists' or White Supremacists' Facebook and Twitter accounts (Stern and Berger, 2015). This in turn reduces the value of the attack in the eyes of the prospective killers and shifts the $\pi()=$. locus downwards, thus reducing the number of active killers. However, parameter $\alpha$ can also be used to provide an alternative explanation to the surprising overrepresentation of engineers among violent extremists, be they Islamists or extreme right wingers, recently uncovered by Gambetta and Hertog (2016). The latter invoke personality traits that lead these people to selfselect into engineering studies and sometimes into violent extremism. In the present framework, engineers would have a lower $\alpha$ than the other potential killers, giving them a 
cost advantage over them in performing high-quality attacks and inciting more of them to strike even at relatively low values of $n$. Hence, the present model predicts that engineers should be overrepresented among killers, but should also frequently have a leading or even founding role in terrorist organizations, as Gambetta and Hertog (2016) have observed. Correlatively, this would explain why lone wolves like Merah or Breivik, with a different educational experience, perpetrated low-skill attacks. By contrast, Gambetta and Hertog found that very few graduates in social sciences or humanities figure prominently among violent extreme-right or Islamist terrorists, while their presence was overwhelming in the European extreme-left groups of the 1970-80s. This is arguably due to either their high $\alpha$ or their high $\beta(k)$ (or both) as these groups specialized in low-casualties and precisely-targeted assassinations (Gambetta and Hertog, 2016).

Then, one might think of shifting the collateral damage function $\mu m(n)$, i.e., increasing $\mu$, by subsidizing European Jews' emigration to Israel when anti-Semitic attacks occur. This might be an effective, though roundabout, course of action. But it may have unfortunate side effects that social welfare considerations should take into account, as this would entail a clear loss for those remaining behind. Another worrying tactic to shift $\mu m(n)$ may involve actions that are unacceptable under the rule of law - such as retaliatory actions against random, innocent Muslims to increase the psychological pressure on the guilty ones. However, although such unacceptable policies are clearly out of question, there remains the possibility of clarifying the debate about these collateral damages by sensitizing the exposed groups about their magnitude and bringing out in the open the tradeoffs involved, which ISIS propaganda is carefully hiding. Finally, and perhaps most importantly, the effectiveness of this course of action depends on the potential killers' subjective evaluation of this externality: the pure Herostratic type, with a $\beta(k)$ close to zero, will be totally unresponsive. However, a 
sensitization campaign of the kind just discussed might be a way to raise $\beta(k)$ for some borderline anomic potential killers, assuming that their low $\beta(k)$ is due more to ignorance than to sheer indifference.

Finally, a further word of caution is in order. All the tools so far discussed work when the outcome is at the zero-profit Nash equilibrium of Proposition 2. The existence of this equilibrium is guaranteed, among other things, by the assumption of an unlimited supply of potential killers. However, nothing rules out the possibility of a corner solution, which would occur when there is a finite upper bound on $k \leq \bar{k}$ and this maximum number of potential killers is so small that the actual number of active killers is equal to it and lower than the zeroprofit equilibrium number $\bar{n}=\bar{k}<n^{*}=k^{*}$. In this case, all the potential killers cross the line because all of them have a strictly positive profit from doing it - condition (10) would still hold if $k$ were free to increase without bounds but the upper bound prevents this. Then, as the number of active killers is just determined by the existing number of potential killers, we do not learn much from the model. In this case - as one would expect from a corner solution - a small parameter change that shifts down the $\pi()=$.0 locus somewhat might have no effect on the equilibrium outcome. So it seems that Herostratic killing must be popular enough for the policy tools reviewed above to work; condition (9) of Proposition 2, however, ensures that these killers will be active even when they are rare. There is no obvious defense against this.

This comment also applies to the Herostratic channel discussed next.

\subsection{The Herostratic channel}

Work on the shift parameter $\psi$, which controls the $v($.$) function, seems to be the$ policy course that specifically targets the Herostratic syndrome and at the same time minimizes the negative side effects. This is more easily said than done, however. Naming and 
shaming the killer will not work: eternal shame is exactly the killer's aspiration. The ideal solution would be to track down and strike at the killer's following, since this is a kind of cult that perpetuates the memory of the martyr. But unlike the cult of martyrs analyzed in Ferrero (2013), in which the followers praise, cherish and remember the martyr because in their eyes he or she was extraordinarily "good", here they remember him because he was extraordinarily "bad"; so whereas in the "good" case heaping shame and ridicule on the martyr and turning the followers' devotion away from it might work, here, paradoxically, one would have to counter the voluntarily chosen shame by publicly arguing that the act was not so bad after all - a prospect that cannot even be seriously entertained. Furthermore, as the American TV serial The Following nicely illustrates, persecuting the cult may even have the perverse effect of thrilling the followers and galvanizing them into action, in imitation of their hero. Here it may be helpful to note that often even the most outrageous views and the most heinous crimes are endorsed and cherished by groups of contrarians who give rise to a cult similar to those celebrating "good" heroes, martyrs, and saints. We have seen that the school shooting epidemic can be understood as a moving cult of heroes; and today on the web there are fan groups dedicated to almost anything, including serial killers, spree killers, Nazis, and what not. If so, striking down these cults and shutting down their websites can certainly help. However, the pure Herostratic character does not require the existence of such a supporting group; even if he should expect universal hate as an aftermath, it is the notoriety itself that spurs him into action. Then the only recourse seems to be the punishment already enacted in antiquity: obliteration of the perpetrator's name from all records.

However, as we have seen, the name ban ultimately failed for Herostratos himself. ${ }^{4}$ For one thing, the extent of the enforcer's reach was crucial: the reach of the Greek city-states

\footnotetext{
${ }^{4}$ It is interesting that at a much earlier time, a name ban was decreed by God on Amalek, an arch-enemy of the Israelites during the period of their exodus from Egypt: they were enjoined to "blot out the remembrance of Amalek from under heaven" (Deuteronomy 25: 19; cf. Exodus 17: 14). This ban too obviously failed as the
} 
did not extend beyond the city's territory; this improved as the Roman Empire gradually came to encompass most of the Mediterranean world. Even then, the Herostratos case shows that the enormity of the deed itself carried the day: as the destruction of the temple could not be forgotten, the perpetrator's name would sooner or later resurface. Furthermore, as Borowitz's (2005, chap. 1) account makes clear, in most cases of damnatio memoriae that were recorded in antiquity, the penalty was effective because it was inflicted on socially or politically prominent individuals, whose family stood to lose from the obliteration of the man's record. An inter-generational punishment was thus involved, as in Azam (2005). By contrast, here we are typically dealing with nobodies who strive to become somebodies and whose family ties are irrelevant. Finally, the effectiveness of the penalty was in part contingent on the offender's vulnerability to some detail of it; in ancient Rome, for example, the offender's family home was razed, which made such a basic family custom as the cult of ancestors impossible. By contrast, religion is irrelevant in the pure Herostratic criminal.

If such a punishment was so difficult effectively to enforce in traditional societies, the prospects for its application in the age of the internet look even less encouraging. It would involve a restriction of media freedom censoring the sensational reports of Herostratic attacks or - perhaps more realistically - a convincing campaign showing that these killers all belong to the same type of psychopaths who deserve compassion more than infamy or hatred, thus downgrading their reputation and frustrating their quest. However, there are milder methods of spoiling the Herostratic killers' names that might have some marginal impact. The model suggests that the aim is in fact to trivialize these attacks, instead of sensationalizing them as the media tend to do today. A possible solution might be a centralized record-keeping of the different types of such attacks that would give them a serial number. Then, the media would only mention their code numbers, while the names of the perpetrators could be found on a ritual curse against the most egregious enemies of the Jewish people. 
web page in the list of all those who perpetrated similar crimes before. For example, EJK2678 would mean "the $2678^{\text {th }}$ killer of European Jews", SCK136 would mean "the $136^{\text {th }}$ killer of children at school", or PC59 would mean "the $59^{\text {th }}$ plane crasher".

In the same vein, the mainstream media should put more emphasis on the cases where ISIS and the other Jihadist groups are killing Muslims, especially in the Middle East and North Africa, where Muslim civilians and soldiers are mowed down by the thousands, and should invest in a carefully attended body count. Prospective Jihadists would then realize that, despite the distorted image broadcasted by Western media, Jihad is currently mainly about killing fellow Muslims, sometimes branded by a takfir (accusation of apostasy) in a highly disputable fashion. Still, as far as Jihadists or White Supremacists are concerned, quite a lot of the publicity they value is not conveyed by official news channels, but by the social media where praise for the attacks and the most gory videos can be posted. Stern and Berger (2015) discuss what the main operators, Twitter in particular, and counter-terrorist organizations are prepared to do to disrupt these communication channels and the value of letting some of it come out as a source of information for the police.

A final policy implication that is related to the publicity parameter highlights the areas and groups that represent the greatest risk and are therefore most in need of attention to early warnings. In both terrorism studies and criminology, researchers normally rely on datasets of previous cases and on this basis engage in profiling of the typical perpetrator. So for example the typical school shooter in the U.S. is a white male student or former student, possibly with grievances toward his peers or his school. A typical Islamic suicide terrorist is a young, unmarried male Muslim who underwent a process of radicalization either in a war-torn, foreign-occupied Muslim-majority country or in some backwater of disaffected, alienated residents of western societies with a Muslim background. But if the quest for notoriety at all costs is the basic motive, the prospective attacker will try to get away from the crowd of his 
peers and overturn the established profile. Explorers of virgin grounds make history, while those who follow in their path less and less so. The next Herostratic killer, then, is likely to still belong in the class of school massacres or Islamic terrorism, so as to permit comparison and gauging against previous attackers, but to possess personal characteristics that are nontypical and select targets and methods of attack that are special and unprecedented.

For some examples, Christian churches and church groups have been targeted in various countries of the world, but a strike at the Vatican itself would indeed make headlines. As discussed in a previous section, world-class monuments that are unique and irreplaceable have already proven to be attractive targets. There are very few and disconnected terrorist incidents using unconventional mass-destruction weapons to date, so an attack with, say, poison gas (to say nothing of a nuclear device) would be big news. Children have been among the victims in many instances but a suicide attack targeted at an audience of teenage girls, as happened at a concert in Manchester in May 2017, was a novel turn.

As to personal characteristics, gender stands out. Suicide terrorism used to be a male occupation except in a few specific organizations (like the Chechen insurgents and Sri Lanka's Tamil Tigers), but since the beginning of the century female participation has been rapidly increasing even among Islamists worldwide (Bloom, 2005, 2011). As to mass killers, even the Chechen separatists involved only men in the attack at the Beslan school in North Ossetia in September 2004 that killed 385 people. So far, women have not been found, except in supporting roles, among homegrown Islamic groups and lone wolves in Europe, nor had they been found in the U.S. before the San Bernardino massacre of December 2015; so a wave of female killers seeking fame is to be expected here. This is even more the case for school shootings, where at least in the US the perpetrators have so far all been males. As discussed in a previous section, the epidemics in its current form will sooner or later begin to die out as the drive to emulate and surpass the predecessors' body count can only go so far. 
But a turn to female shooters might well start to draw on a vast, untapped pool of potential perpetrators.

\section{Conclusion}

This paper has made the perfectly obvious point that perfectly rational agents can have very weird preferences. This has been done by embedding in a game-theoretic framework the Herostratos syndrome that some authors, including some psychologists, have identified as a potential explanation for some odious crimes. The latter are perpetrated by individuals who prefer to be known for their infamous acts rather than remaining anonymous. This framework seems to shed some useful light on a series of events that shook European countries in the 2010s, when different individuals perpetrated some spectacular lethal attacks. The key point is that in some of these cases, the killers are perpetrating some crimes that are in contradiction with their proclaimed objectives. In some others, they openly admit that the quest for infamy is their only motive. The model analyzed above helps us to understand these different cases in a unified framework based on the rational-choice postulate. We have provided a set of simple conditions that ensure existence of a well-behaved Nash equilibrium where Herostratic killers are competing with a view to make a name for themselves in infamy. Although this behavior may legitimately be diagnosed as psychopathic, because of the weird preferences that it reveals, this model shows that it would be highly misleading to invoke any form of irrationality to explain it. We have finally offered some policy suggestions that focus on ways and means to reduce the publicity the killers enjoy and thus frustrate their quest for notoriety. Clearly, some hard policy-oriented thinking is the task ahead. 


\section{Appendix A: Multiple equilibria}

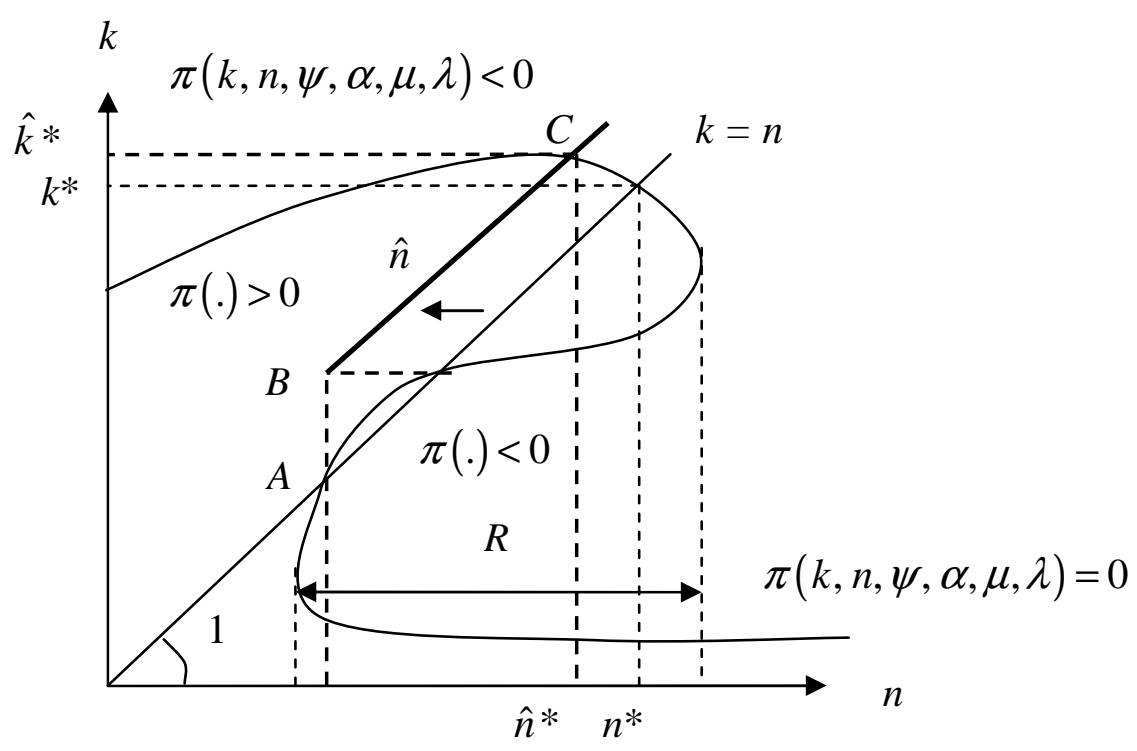

Figure A1: A case where (7) fails over a range $R$

Figure A1 depicts the case where the single-crossing condition (7) fails over a given range $R$. This may occur because $\beta^{\prime}(k)<0$ becomes too low relative to $\theta^{\prime}(k)$, for given values of $v($.$) and \mu m(n)$, over a certain range, before (7) holds again; in this case $\pi($. may become negative over a certain range before turning positive again. Then, $n^{*}$ would not be the unique Nash equilibrium, as can be checked using Figure A1, where the potential killers belonging to the interval $] A B$ [ of the $k$ axis for which the $k=n$ line lies to the right of the $\pi(k, n, \psi, \alpha, \mu, \lambda)=0$ locus in the interim range are facing $\pi(k, n, \psi, \alpha, \mu, \lambda)<0$ for every $n \geq k$. These "passionate borderline" potential killers, in the terms of table 1 , have a high enough $\beta(k)$ to refrain from killing despite a high $\theta(k)$ corresponding to their relatively low $k$. Some messy manipulations of the diagram show that an equilibrium might exist in this case with two disjoint sets of killers and a total number of killers $\hat{n}^{*}<n^{*}$ such that the highest index of the active killers would be $\hat{k}^{*}>\hat{n}^{*}$. To see this, exclude the inactive 
potential killers and draw the $\hat{n}$ line from $B$ parallel to the $k=n$ line as shown by the leftward-pointing arrow. A Nash equilibrium is found at the intersection of this line with the $\pi(k, n, \psi, \alpha, \mu, \lambda)=0$ locus at point $C$. However, if we think of a slow-moving groping process along the $k=n$ line starting from low values of $k$, then this process would end up at Nash equilibrium $A$ beyond which $\pi()<$.0 up to point $B$. A discontinuous jump would then be needed to move beyond $B$ where $\pi()>$.0 until $C$ is reached. Notice that these borderline potential killers could be turned into Herostratic killers by a downward shift of the $\pi()=$. locus in this neighborhood; hence, the existence of equilibrium $A$ and the entailed need for a discontinuous jump from $A$ to $B$ depends on the configuration of parameter values. For example, a large enough fall in $\alpha$ or increase in $\psi$ (see equations (3), (6), and the discussion in section 5) would expand the $\pi()>$.0 area, thus shifting the $\pi()=$.0 locus downwards in the neighborhood of $[A B]$ until it could make the latter empty. This could trigger a massive wave of Herostratic killing starting from $A$ as the $\pi()<$.0 area shrank and a higher $k^{*}=n^{*}$ point would become the unique equilibrium.

Figure A2 discusses another case where three intersections may exist between the $\pi(k, n, \psi, \alpha, \mu, \lambda)=0$ locus and the $k=n$ line because (8) fails although (7) holds. However, disjoint sets of active killers cannot exist in the Nash equilibrium in this case. To see this, imagine again a slow-moving groping process along the $k=n$ line starting from low values of $k$. Here again, the process would get stuck at $A$ as in the previous case. However, if a jump occurred to move beyond $B$, all the potential killers $k \in] A B$ ] would become active as $n$ would become large enough for them to cross the line and the process would converge eventually to equilibrium $C$ with $k^{*}=n^{*}$. Hence, in this case, the borderline potential killers $k \in] A B$ ] are just high-threshold Granovetter followers that jump into the bandwagon when 
$n$ becomes large enough, as discussed in section 3.2. Locally excessive addiction means that any additional attack steeply increases the expected impact on public opinion $v\left(n, q^{*}, \psi\right)$ in this neighborhood, in contrast to a fairly flat range just preceding it on its left. This also captures a threshold effect.

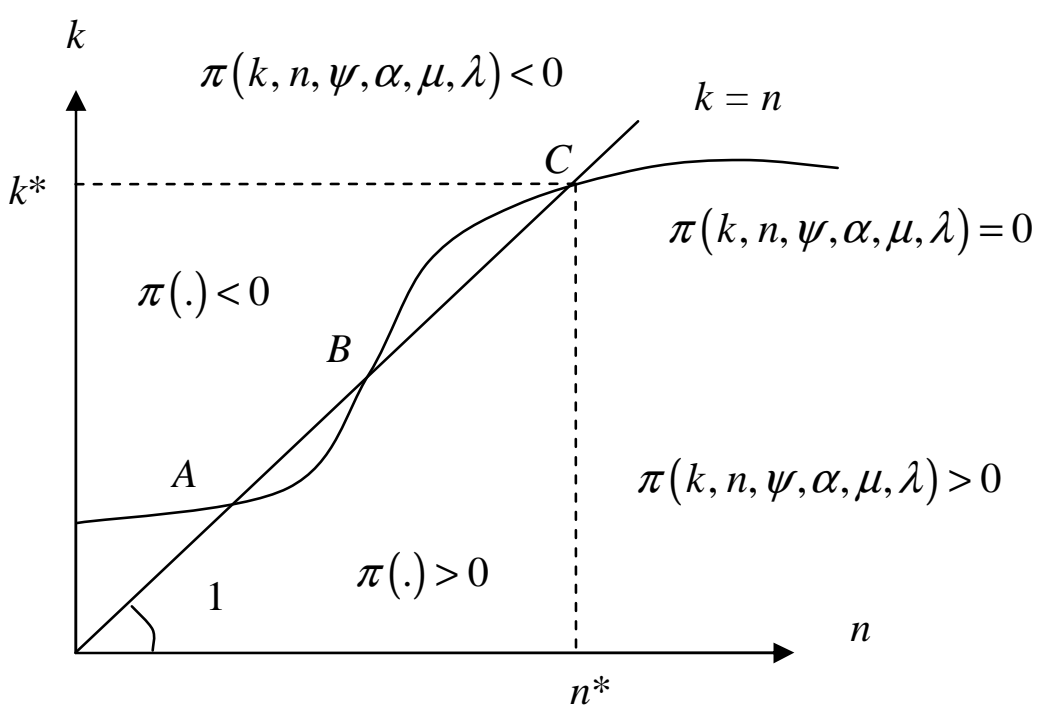

Figure A2: The case of locally excessive addiction

This potential need for a discontinuous jump in the groping process is ruled out if the slope of the $\pi(k, n, \psi, \alpha, \mu, \lambda)=0$ locus is always lower than 1 in the $\{k, n\}$ space:

$$
\left.\frac{d k}{d n}\right|_{\pi=0}=\frac{\beta(k) \mu m^{\prime}(n)-\theta(k) \partial v / \partial n}{\theta^{\prime}(k) v(n, q, \psi)-\beta^{\prime}(k) \mu m(n)}<1, \forall n .
$$

The denominator of (12) is always negative by (7) so that (12) requires that the Bounded Addiction condition (8) holds, as it is obtained by rearranging the terms while the term in square brackets in (8) is negative. 


\section{Appendix B: Comparative statics}

Consider the Nash equilibrium with $\pi()=$.0 and $k^{*}=n^{*}$. Since the single-crossing condition (7) holds for any $k$, it will hold also for $k^{*}=n^{*}$. Let us compute the change in the equilibrium level of $n^{*}$ due to changes in $\{\psi, \alpha, \mu, \lambda\}$, i.e., the shift of the intersection of the $\pi()=$.0 locus with the $k=n$ line in Figures 1 or 2 . From (1) and (6), we can write the zeroprofit condition when $k^{*}=n^{*}$ as:

$$
\pi\left(n^{*}, \psi, \alpha, \mu, \lambda\right)=\theta\left(n^{*}\right) v\left(n^{*}, q^{*}, \psi\right)-\alpha c\left(q^{*}\right)-\beta\left(n^{*}\right) \mu m\left(n^{*}\right)-\lambda=0
$$

Then, taking the total differential, taking due account of the first-order condition $\theta(k) \partial v / \partial q=\alpha c^{\prime}\left(q^{*}\right)$ and re-arranging the terms yields:

$$
d n^{*}=\frac{c\left(q^{*}\right) d \alpha+\beta\left(n^{*}\right) m\left(n^{*}\right) d \mu+d \lambda-\theta\left(n^{*}\right) \frac{\partial v}{\partial \psi} d \psi}{\theta\left(n^{*}\right) \frac{\partial v}{\partial n^{*}}+\theta^{\prime}\left(n^{*}\right) v-\beta^{\prime}\left(n^{*}\right) \mu m\left(n^{*}\right)-\beta\left(n^{*}\right) \mu m^{\prime}\left(n^{*}\right)} .
$$

The Bounded Addiction condition (8) ensures that the denominator of (B2) is negative. Then, the partial derivatives with respect to the four policy tools can be easily derived from (B2), confirming that the cost parameters $\alpha, \mu$ and $\lambda$ have negative impacts on $n^{*}$, while the media environment parameter $\psi$ has a positive one.

Acknowledgments. An earlier version of this paper was presented at the annual meeting of the European Public Choice Society (University of Freiburg, March 30 - April 2, 2016) and at the $16^{\text {th }}$ Jan Tinbergen European Peace Science Conference (Catholic University of Milan, June 20-22, 2016); participants in both events provided interesting discussion. The authors are particularly indebted to Ranan Kuperman and Soeren Schwuchow for helpful comments. Helpful comments by an anonymous reviewer are gratefully acknowledged. 


\section{References}

Agnich, L.E., 2015, “A comparative analysis of attempted and completed school-based mass murder attacks", American Journal of Criminal Justice, 40 (1), 1-22.

Apolte, T., 2017, "I hope I die before I get old. The supply side of the market for suicide bombers", Discussion Paper 1/2017, Center for Interdisciplinary Economics, University of Müenster.

Azam, J-P, 2005, "Suicide bombing as inter-generational investment", Public Choice, 122 (12), 177-198.

Azam, J-P, 2012, "Why suicide terrorists get educated and what to do about it", Public Choice, 153 (3-4), 357-373.

Azam, J-P. and M. Ferrero, 2016, "Killing for the sake of infamy: The Herostratos syndrome and what to do about it”, Peace Economics, Peace Science and Public Policy, 22 (4), $357-364$.

Bartlett, R., 1993, The Making of Europe. Conquest, Colonization and Cultural Change 9501350, London: Allen Lane.

Berman, E., 2009, Radical, Religious, and Violent: The New Economics of Terrorism, Cambridge (MA): MIT Press.

Bloom, M., 2005, Dying to Kill. The Allure of Suicide Terror, New York: Columbia University Press.

Bloom, M., 2011, Bombshell. The Many Faces of Women Terrorists, London: Hurst.

Borowitz, A., 2005, Terrorism for Self-glorification: The Herostratos Syndrome, Kent (OH): Kent State University Press.

Crouch, D., 2015, "Sweden school attack: Police treat killing of pupil and teacher as racist hate crime", The Guardian, October 23. 
Eswaran, M. and H. Neary, 2015, "Identity and terrorism", paper presented at the ASREC Conference, Boston (MA), March 20-21.

Ferrero, M., 2006, “Martyrdom contracts”, Journal of Conflict Resolution, 50 (6), 855-77.

Ferrero, M., 2013, “The cult of martyrs”, Journal of Conflict Resolution, 57 (5), 881-904.

Filiu, J.-P. (2011): Apocalypse in Islam, translated by M.B. DeBevoise, Berkeley: University of California Press.

Gambetta, D. and S. Hertog, 2016. Engineers of Jihad. The curious connection between violent extremism and education, Princeton: Princeton University Press.

Gladwell, M., 2015, “Thresholds of violence. How school shootings catch on", The New Yorker, October 19.

Granovetter, M., 1978, “Threshold models of collective behavior”, American Journal of Sociology, 83 (6), 1420-1443.

Kepel, G., 2015, Terreur dans l'hexagone, with A. Jardin, Paris: Gallimard.

Lankford, A. and N. Hakim, 2011, "From Columbine to Palestine: A comparative analysis of rampage shooters in the United States and volunteer suicide bombers in the Middle East”, Aggression and Violent Behavior, 16 (2), 98-107.

Larkin, R.W., 2009, “The Columbine legacy. Rampage shootings as political acts”, American Behavioral Scientist, 52 (9), 13309-1326.

Moutouh, H., 2013, 168 Heures chrono. La traque de Mohamed Merah, Paris: Plon.

Nesser, P., 2015, Islamist Terrorism in Europe. A History, London: Hurst.

Nussbaum, M.C., 2007, The Clash Within. Democracy, Religious Violence, and India's Future, Cambridge (Mass): Belknap Press.

Pape, R., 2006, Dying to Win. The Strategic Logic of Suicide Terrorism, New York: Random House Trade Paperbacks. 
Phillips, P.J, 2011, "Lone wolf terrorism", Peace Economics, Peace Science and Public Policy, 17 (1).

Phillips, P.J and G. Pohl, 2014, "Prospect theory and terrorist choice", Journal of Applied Economics, 17 (1), 139-160.

Preti, A., 2008, "School shooting as a culturally enforced way of expressing suicidal hostile intentions", Journal of the American Academy of Psychiatry and the Law, 36, 544550.

Rocque, M., 2012, "Exploring school rampage shootings: Research, theory, and policy", The Social Science Journal, 49 (3), 304-313.

Stern, J. and J.M. Berger, 2015, ISIS. The State of Terror, London: William Collins.

Wintrobe, R., 2006a, "Extremism, suicide terror and authoritarianism", Public Choice, 128 (1-2), 169-195.

Wintrobe, R., 2006b, Rational Extremism: The Political Economy of Radicalism, Cambridge: Cambridge University Press. 